\title{
A ressurreição do volume morto do Sistema Cantareira na Quaresma
}

\author{
Rubem L. Porto* | Monica F.A. Porto | Marco Palermo
}

DOI: http://dx.doi.org/10.4322/dae.2014.131

O Sistema Cantareira está em crise. Trata-se do maior dos sistemas produtores de água para abastecimento da Região Metropolitana de São Paulo, capaz de armazenar 978 milhões de metros cúbicos para regularizar o regime dos rios que constituem o sistema.

Este sistema é responsável pelo abastecimento de cerca de 9,4 milhões de pessoas, população que por si só seria suficiente para constituir a terceira maior população urbana do país. Em início de abril o sistema encontrava-se com cerca de $12,5 \%$ de sua capacidade útil ou seja 122 milhões de metros cúbicos. Segundo as curvas que guiam a operação do sistema, elaboradas pelos órgãos gestores de recursos hídricos da União e do Estado, o armazenamento atual deveria ser superior a 60\%, ou seja, 590 milhões de metros cúbicos (DAEE, 2004).

Inúmeras razões vêm sendo apontadas, no meio técnico e na mídia, para tal crise que, sem dúvida, é muito crítica. A mídia vem exercendo importante papel ao manter o assunto em evidência. Técnicos e especialistas utilizam dados e conhecimentos para dar respostas a uma série de questões, com vistas à superação da crise e aprimoramento de políticas de operação, critérios de planejamento e planos de contingência. Os órgãos responsáveis pelo abastecimento das cidades supridas pelo Sistema Cantareira trabalham com afinco para administrar a crise e a minimizar os prejuízos da sociedade. Todas estas ações são muito importantes. É essencial que não sejam esqueci- das tão logo a crise seja superada.

Justificadamente o assunto vem sendo debatido, com bastante frequência, na mídia e eventos técnicos. Entretanto, muitas das análises e opiniões apresentam falhas de diversas naturezas que parecem ter origem em conhecimentos parciais da questão, falta de base técnica ou científica, quando não por interesses políticos e posições ideológicas. Estes tipos de análise não contribuem em nada para a administração da crise e muito menos para as políticas estratégicas do setor. Pelo contrário, criam ruídos, nublam visões, criam problemas inexistentes e podem induzir a ações inadequadas, anti econômicas e desastrosas.

Embora o problema, em seu todo, seja bastante complexo e merecedor de análises profundas e abrangentes, é essencial, no momento, a tomada de medidas de emergência. Desta forma procurou-se reduzir o objetivo deste texto a lançar luz sobre o aproveitamento do volume morto dos reservatórios Jaguari-Jacareí e Atibainha, uma das medidas mais importantes e efetivas, dentre as que foram adotadas para superação da crise.

\section{O Sistema Cantareira}

A história do Sistema Cantareira iniciou-se na década de 60 quando o Governo do Estado de São Paulo decidiu colocar a questão do aproveitamento dos recursos hídricos do Alto Tietê em patamares condizentes com o porte e a complexidade do problema. Em 1968 foi publicado o relatório final do plano intitulado

Nota dos autores: A elaboração deste texto foi iniciada durante o período da quaresma de 2014 e concluída após o término das obras em maio do mesmo ano. Diferenças pouco significativas certamente existirão entre as características finais das obras e as citadas no presente artigo, principalmente no que se refere a algumas cotas e volumes. Entretanto, estas diferenças em nada alteram as conclusões do texto. 
Desenvolvimento Global dos Recursos Hidricos das Bacias do Alto Tiete e Cubatão- Plano Diretor de Obras (DAEE 1968), elaborado sob a responsabilidade do Departamento de Águas e Energia Elétrica e pelo um Consorcio Hibrace, constituído por três firmas de Consultoria.. Este estudo caracterizou-se por uma abordagem ampla das questões de recursos hídricos das regiões do Alto Tietê, Baixada Santista e Bacia do Rio Piracicaba. Foram abordados o abastecimento de água, a questão da coleta, disposição e tratamento dos esgotos e o controle de cheias destas regiões. Foram ainda executados anteprojetos de inúmeras de obras para aquilatar questões de viabilidade técnica e econômica das alternativas concebidas. O relatório final dos estudos apontou o Sistema Cantareira, esquematizado na Figura 1, como prioritário para resolver os crônicos problemas de abastecimento de água da Região Metropolitana de São Paulo.

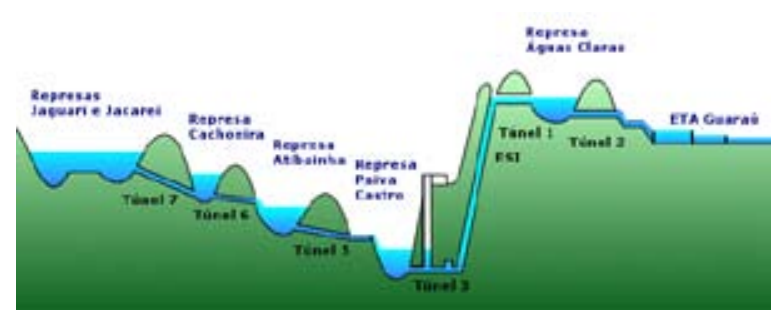

Figura 1- Perfil esquemático do Sistema Cantareira

Em 1966, teve início a construção do Reservatório Paiva Castro, no rio Juqueri, a primeira obra do Sistema Cantareira. A esta pequena obra seguiram-se outras de maior porte, situadas nas cabeceiras da bacia do Rio Piracicaba. Nesta última foram construídas barragens para a formação dos reservatórios de Cachoeira, Atibainha e Jaguari-Jacarei. O Sistema Cantareira fornece cerca de $33 \mathrm{~m}^{3} / \mathrm{s}$ para a Região Metropolitana de São Paulo, que corresponde aproximadamente à metade de toda a água consumida por esta região.

As interligações entre os reservatórios são feitas por túneis e canais. Os reservatórios criados pelas barragens dos rios Jaguari e Jacarei unem-se por um canal e formam um único reservatório chamado Jaguari-Jacareí. O Jaguari-Jacareí e o Cachoeira são ligados por um túnel de 5,6 quilômetros, Outro túnel, este de 5 quilômetros, faz a ligação entre os reservatórios do Cachoeira e Atibainha. Mais dois túneis, de 10 e de 1 quilômetro, ligam, respectivamente, o Reservatório de Atibainha ao do Juqueri, e este à Elevatória de Santa Inês. Esta elevatória bombeia o total das águas captadas para o Reservatório de Águas Claras, construído no alto da Serra da Cantareira. Desse reservatório, as águas passam, por gravidade, à Estação de Tratamento do Guaraú.

Para vencer o obstáculo da Serra da Cantareira foi construída a Estação Elevatória de Santa Inês, com quatro grupos de recalque de 20.000 HP. Três desses grupos estão capacitados a bombear os $33 \mathrm{~m}^{3} / \mathrm{s}$. O quarto grupo constitui unidade de reserva. Impulsionada pelas bombas, a água proveniente dos reservatórios é elevada a 120 metros, até o alto da serra. Por gravidade, através de um canal de 950 metros e um túnel de 800 metros, atinge o Reservatório de Águas Claras.

O Sistema Cantareira afeta o restante da bacia do Piracicaba de duas formas. Por um lado traz benefícios de controle de cheias e regularização de vazões. firmes. Por outro é inegável que a redução de cerca $30 \mathrm{~m}^{3} / \mathrm{s}$, em média, revertidos para São Paulo podem trazer consequências prejudiciais ao desenvolvimento da Bacia do Piracicaba, se a questão não for administrada de acordo com os princípios de gestão integrada e sustentável dos recursos hídricos.

A questão do aproveitamento dos recursos hídricos das bacias do Alto Tietê e do Rio Piracicaba é, na verdade, apenas mais um exemplo dos complexos problemas de gerenciamento de recursos hídricos que ocorrem regiões mais desenvolvidas do país e, de forma geral, em inúmeras regiões do planeta. Agravam-se os conflitos entre usos para abastecimento doméstico, industrial e agrícola à medida que a regiões se desenvolvem. $\mathrm{O}$ abastecimento da Região Metropolitana de São Paulo depende grandemente da reversão do Sistema Cantareira. Por outro lado; a bacia do Piracicaba sofre com problemas semelhantes, principalmente em um de seus formadores, o rio Atibaia, onde às limitações de vazão, prevalecem problemas de qualidade das águas, degradadas que são por efluentes urbanos, industriais e agrícolas. 


\section{A anatomia da crise atual}

No dia primeiro de outubro de 2013 o armazenamento disponível em todo o Sistema Cantareira era de $40 \%$ de seu volume total, considerado normal para esta época no ano, de acordo com as curvas de operação do Sistema. No dia primeiro de novembro o nível havia caído para cerca de $36 \%$, sem dar motivo para maiores preocupações pois os meses seguintes, de dezembro a março, são os mais chuvosos do ano e era esperado que o Sistema se recuperasse significativamente até o inicio do período seco de 2014 .

No entanto a hidrologia mais uma vez confirmou que a "pior seca ainda está por vir". Nos meses seguintes, até meados de abril, o reservatório perdeu cerca de $28 \%$ de sua capacidade em uma taxa praticamente constante de $4 \%$ ao mês, até atingir os atuais $12,5 \%$. A explicação para o esvaziamento pode ser constatada pela tabela abaixo:

Nota-se que o déficit do período 2013-2014 em relação à seca mais severa observada até 2013 é aproximadamente 30\% do volume útil do Sistema, ou seja, 293 milhões de metros cúbicos. Em outras palavras, é inevitável que os reservatórios do Sistema estejam hoje com volumes muito pequenos, pois o volume útil do Sistema Cantareira foi dimensionado com base na seca de 1953. A situação só não é mais critica porque o rio Juqueri apresentou, no mesmo período, vazões superiores à média e assim a Sabesp conseguiu administrar a crise sem grandes prejuízos à população. Foi impor- tante também a redução do consumo que se verificou, principalmente a partir de março de 2014, em razão de medidas de gestão da demanda. As medidas de maior efeito foram a instituição do bônus por economia de água, a importação de águas de outros sistemas para abastecer a região normalmente atendida pelo Cantareira e as campanhas de esclarecimento dirigidas à população.

Pode-se discutir com maior ou menor propriedade se algumas medidas tardaram a ser implantadas. Pode-se perguntar também se não seria possível prever a ocorrência de um período extremamente crítico, exatamente nos meses mais chuvosos do ano. São questões que provavelmente ficarão sem respostas e no momento são irrelevantes, embora devam ser cuidadosamente estudadas para formular novas estratégias para o futuro.

Um fato porém é incontestável: a Tabela 1 abaixo é baseada nos dados mais fidedignos de que se dispõe hoje e mostra que a crise é de natureza hidrológica. Mostra também que estaríamos vivendo uma situação crítica, quaisquer que fossem as medidas de gestão de demanda que pudessem ter sido tomadas em fins de 2013 ou início de 2014.

\section{Medidas de emergência para a administra- ção da crise}

A questão realmente importante no momento é que medidas podem ser tomadas para administrar a crise de forma a causar os menores prejuízos possíveis à população. A mar-

\begin{tabular}{|c|c|c|}
\hline & $\begin{array}{l}\text { Milhões de } \\
\text { metros cúbicos }\end{array}$ & $\begin{array}{l}\text { Percentagem do } \\
\text { Volume Útil do Sistema }\end{array}$ \\
\hline Armazenamento disponível no Sistema 01/out/2013 & 391,2 & 40 \\
\hline $\begin{array}{l}\text { Afluxo esperado ao Sistema Cantareira de outubro a agosto } \\
\text { (média da série) }\end{array}$ & 1187,0 & 121 \\
\hline Afluxo observado de out/53 a ago/53 & 677 & 52 \\
\hline Afluxo observado de out/13 a ago/14 & 385 & 39 \\
\hline Deficit da seca de 1953 em relação ao afluxo médio & 510 & 52 \\
\hline Deficit da seca de 2014 em relação ao afluxo médio & 802 & 82 \\
\hline
\end{tabular}

Tabela 1 - Afluxos ao Sistema Cantareira de outubro de 2013 a março de 2014 
gem de manobra é muito estreita porque não é possível recorrer a medidas estruturais em face do tempo de maturação e construção que estas requerem. Restam as chamadas medidas não estruturais, como campanhas de esclarecimento, utilização de instrumentos econômicos, remanejamento de áreas de suprimento de água, rodízios e algumas poucas mais. Estas medidas já vem sendo tomadas, estão dando resultados, devem ter continuidade e provavelmente deverão ser aprofundadas.

Infelizmente, este tipo atuação de apresenta limites e o risco de que as atuais reservas não durem até a próxima estação chuvosa é muito grande. Torna-se absolutamente necessário aumentar a oferta de água para levar o Sistema Cantareira até o período chuvoso de 2014-2015.

A única forma de aportar "água nova" para o Sistema, no curto horizonte de tempo disponível, é o aproveitamento do chamado volume morto (ou inativo) dos reservatórios Jaguari-Jacarei e Atibainha. Este recurso já foi utilizado no Brasil e em outros países, em casos semelhantes.

Seria difícil imaginar, há alguns anos, que expressões exclusivas do jargão da Engenharia de Barragens se transformassem em notícia de primeira página da mídia.

Aversão ao risco hidrológico, volume morto, volume útil, níveis mínimos e máximos operacionais e até resiliência dos sistemas eram antes conceitos exigidos dos alunos das Escolas de Engenharia, que precisavam estudar para não serem reprovados. Em um processo semelhante ao dos alunos que não se dedicam a fazer a "lição de casa", muitas interpretações inadequadas e opiniões incoerentes apareceram em grande número na mídia.

\section{O aproveitamento do Volume Morto}

O termo Volume Morto é corrente no campo da Engenharia de Barragens e significa, em termos amplos, que se trata de um volume que não é utilizado para as finalidades normais do reservatório. Dependendo de fatores como as finalidades do reservatório, sua topografia e o arranjo de suas estruturas o Volume Morto pode ficar em cotas elevadas, até mesmo nas proximidades do topo da barragem. Não existe nenhuma relação entre este termo técnico e coisa "morta", "podre" ou de "má qualidade". Trata-se, portanto, de um volume inativo, para os objetivos do reservatório, em condições

Figura 2 - Obras de instalação do bombeamento para captação de água do volume morto do Sistema Cantareira

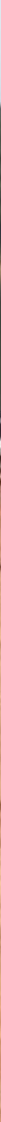


normais de operação.

No caso do Sistema Cantareira, os Volumes Mortos nos Reservatórios de Jaguari-Jacareí, Cachoeira e Atibainha situam-se em cotas altas e não existem razões técnicas ou ambientais que impeçam seus aproveitamentos. Para o entendimento da questão é preciso que as pessoas conheçam as características dos reservatórios do Sistema, pelo menos em sua essência.

Todos os reservatórios do Sistema são dotados de três tipos de estrutura hidráulica: (1) estravazores, para descarregar grandes cheias e evitar o galgamento das barragens, (2) descargas de fundo, situadas em níveis próximos ao fundo dos reservatórios, utilizadas para manter o fluxo dos rios com objetivos ecológicos e de atendimento às demandas das regiões situadas abaixo das barragens e (3) tomadas de transferência de água, situadas em níveis altos, destinadas a alimentar os túneis que transferem água de um reservatório para outro. A Figura 1 mostra esquematicamente os 7 túneis de transferência de água que compõem o Sistema Cantareira.

A Figura 3 ilustra o caso do reservatório Jaguari-Jacarei. Na situação atual o nível d 'água encontra-se pouco abaixo da cota $823,0 \mathrm{~m}$. Quando a superfície do lago baixar até cota do nível mínimo normal (820,8 m) não será possível transferir as águas do Reservatório Jaguari-Jacareí para o Reservatório Cachoeira, nas quantidades necessárias. Atinge-se finalmente o "mal afamado" Volume Morto e o bombeamento deverá ser iniciado. Note-se que este nível está a cerca de 26 metros acima do fundo do reservatório, definido pela cota da descarga de fundo $(795,0 m)$. Esta profundidade equivale a um edifício de oito andares, como esquematizado na figura.

Note-se que por razões topográficas é absolutamente impossível transferir água de um reservatório para outro pela descarga de fundo.

Ao se atingir a cota $820,8 \mathrm{~m}$ o bombeamento do Volume Morto deverá ser iniciado. Para tanto será necessário construir um dique e um canal. A função do dique é garantir a cota mínima para alimentação do túnel e assim transferir a vazão desejada para o Reservatório de Cachoeira. A função do canal é permitir a chegada da água até o pé do dique, uma vez que a superfície da água se afasta com o gradativo abaixamento da cota da superfície do lago. As obras já foram as obras foram concluídas em maio de 2014.

Apenas uma altura de 5 a 6 metros da parte superior do Volume Morto será bombeada (faixa verde da Figura 4). No reservatório Jaguari-Jacarei, esta altura corresponde a cerca de 100 milhões de $\mathrm{m}^{3}$. Aproximadamente o mesmo volume será bombeado do Reservatório de Atibainha. Este total corresponde a aproximadamente $22 \%$ do volume útil do Sistema Cantareira (quase o dobro das reservas atuais) e garantirá uma sobrevida significativa ao Sistema.

Após o bombeamento a altura da coluna d'água remanescente será de cerca de $20 \mathrm{~m}$ (um edifício de 6 andares). É preciso enfatizar que a utilização de volumes inativos constituem estratégias utilizadas para enfrentar crises, e não são incomuns. No Ceará, em anos recentes, utilizou-se a medida para socorrer o sistema que abastece a Região Metropolitana de Fortaleza, que passava por crise semelhante à que vivemos hoje em São Paulo.

\section{Qualidade da Água}

Períodos de seca com criticidade moderada ou mesmo grande costumam ser administrados por meio de medidas não estruturais que em geral são suficientes para superá-los. No presente caso, entretanto, este tipo de medidas é insuficiente e torna-se necessário aportar "água nova" ao Sistema por meio da construção de obras que possam ser concluídas a tempo de evitar colapso do sistema de abastecimento. A única alternativa que atende ao quesito de urgência é o bombeamento de parte do volume morto.

A partir da decisão de realizar o bombeamento começaram a surgir dúvidas e especulações sobre a qualidade da água desta parte do reservatório.

A respeito desta questão, é importante que fiquem perfeitamente claros os aspectos relacionados a seguir:

- Como já visto anteriormente a palavra "morto" neste contexto não guarda nenhuma relação com "deteriorado" ou "podre"; esta palavra refere-se apenas ao fato de que não se usa este volume de água nas condições normais de operação do reservatório. Assim, a água que está no volume morto, ou reserva técnica, é "igual” ao restante do reservatório. 
LabSid Laboratónio de Sistemas de Suporte a Decisōes em Engenharia de Recursos Hidricos e Ambiental Departamento de Engenharia Hidróulica e Ambiental- Escola Politécnica da USP

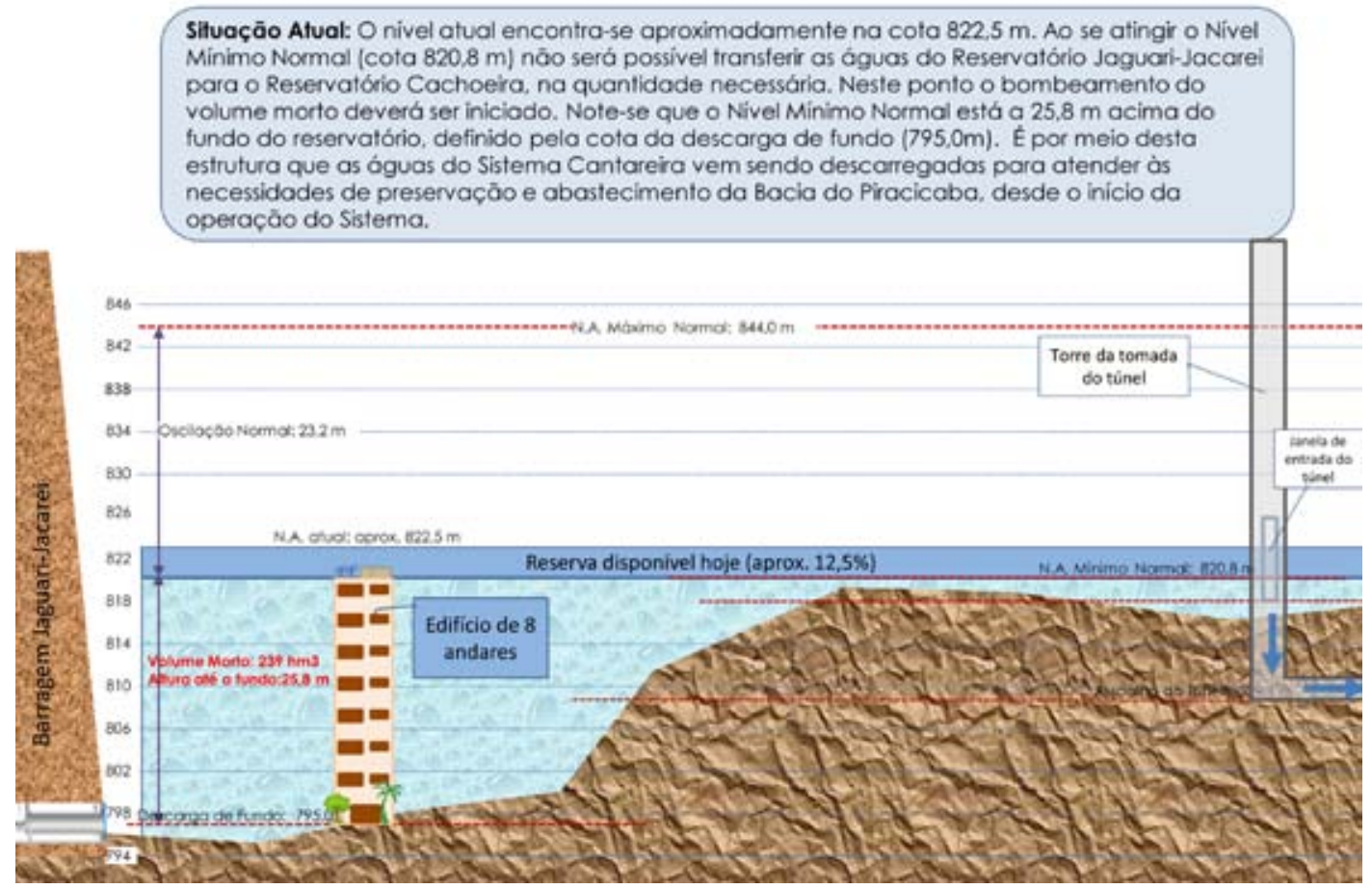

Figura 3- Bombeamento do volume morto; situação atual.

\section{Labial Laboratório de Sistemas de Suporte a Decisōes em Engenharia de Recursos Hidricos e Ambiental Departamento de Engenharia Hidráulica e Ambiental-Escola Politécnica da USP}

Após o Bombeamento: Quando o nivel de água atingir o Nivel Minimo Normal o bombeamento deve ter início. Apenas uma altura de 5 a 6 metros da parte superior do volume morto será bombeada. Esta alfura corresponde a cerca de 100 milhōes de $\mathrm{m} 3$. Volume semeihante será bombeado do Reservatório de Atibainha totalizando cerca de 200 minhöes de $\mathrm{m} 3$. Este volume poderá suprir os atuais niveis de consumo até a estação chuvosa de 2014/2015.

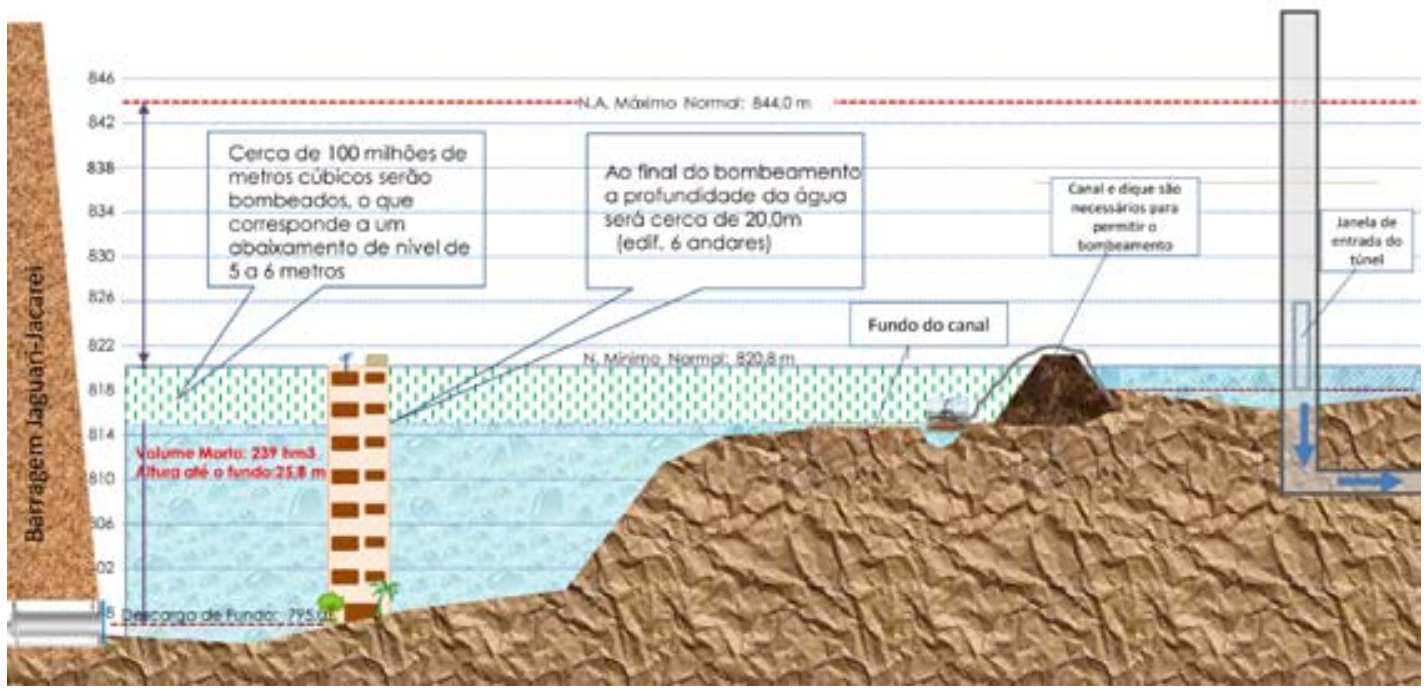

Figura 4-Bombeamento do volume morto; situação após o bombeamento 
- As vazões afluentes ao Sistema Cantareira apresentam boa qualidade da água conforme consta dos relatórios da Cetesb (www.cetesb. sp.gov.br), por exemplo:

...Rio Jaguari, na entrada do Reservatório do Jaguari: ponto de monitoramento CETESB JAGR00002, com observações desde 2004, valor mínimo de Oxigênio Dissolvido observado de $6,1 \mathrm{mg} / \mathrm{l}$, compatível com rios de Classe 1.

- Como as vazões afluentes possuem qualidade boa, não há razão para que as águas do reservatório não sejam de boa qualidade. Não há grandes fatores que impactem negativamente a qualidade das águas nas bacias contribuintes ao Sistema Cantareira

- A água destinada à bacia do Rio Piracicaba e que segue o curso normal dos rios sai do reservatório através de tomadas de fundo. Desde o início da operação do Sistema Cantareira, na década de 70, esta água sai do "volume morto". Não foram observados impactos decorrentes da qualidade da água da vazão que sai dos reservatórios nos trechos imediatamente a jusante das barragens. Eventuais descargas anóxicas que ocorrem durante períodos de estratificação térmica não causam problemas a jusante dos reservatórios, pois a reaeração é muito intensa e as águas atingem níveis adequados de oxigênio dissolvido rapidamente, logo após as barragens.

- O vento e outros fatores provocam a circu- lação das águas dos reservatórios no período do inverno, mantendo, nessa época, as águas misturadas dentro do reservatório, sem que haja diferenças de qualidade da água entre a superfície e o fundo (Porto, 1991).

- Quanto a um possível revolvimento do sedimento do fundo, note-se que as bombas são flutuantes e retiram água da superfície. As profundidades restantes ainda são muito grandes (maiores do que 20m). Assim, a sucção não revolve o sedimento do fundo.

- O monitoramento de qualidade da água nos pontos de bombeamento da reserva técnica dos reservatórios do Jaguari/Jacareí e do Atibaia exigido pelo Ministério Público e realizado pela CETESB indicam qualidade Boa e Ótima do Índice de Abastecimento Público em todas as medições. Estes dados estão disponíveis no site da CETESB.

- As demais variáveis de qualidade da água monitoradas pelas CETESB nesses pontos (Oxigênio Dissolvido, E.Coli, Turbidez e outras) têm-se mantido em condições compatíveis com a classe de enquadramento do corpo hídrico (Classe 1).

- Após a captação nos reservatórios, a água bruta é transferida para a Estação de Tratamento de Água do Guaraú. A ETA-Guaraú produz água de abastecimento para ser distribuída à população em conformidade com o padrão de potabilidade estabelecido pelo Ministério da Saúde.

Figura 5 - Obras de instalação do bombeamento para captação de água do volume morto do Sistema Cantareira

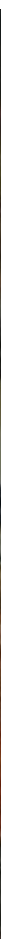




\section{Conclusões}

Os objetivos deste artigo foram, principalmente o fornecimento de informações fidedignas e o esclarecimento de dúvidas a respeito do bombeamento do volume morto do Sistema Cantareira. É crença dos autores que a população e o meio técnico tenham direito a estas informações e se sentirão recompensados, mesmo que apenas pequena parte de seus objetivos tenha sido alcançada.

A essência do trabalho pode ser resumida como segue:

- Mesmo após o bombeamento do volume morto os reservatórios não secarão. Ainda restarão volumes significativos nos lagos do Sistema Cantareira (cerca de 200 milhões de metros cúbicos). As cotas dos reservatórios permanecerão muito acima das cotas das tomadas de fundo. Estes volumes e cotas (formados apenas com o restante Volume Morto) são da mesma ordem de grandeza dos reservatórios do Sistema Alto Tietê, do Reservatório Guarapiranga e muito maiores do que o reservatório de Paiva Castro, este do próprio Sistema Cantareira.

- Em 15 de maio de 2014 as reservas do Sistema Cantareira eram de $7,81 \%$, ou seja, cerca de $76 \mathrm{hm}^{3}$, nível mais baixo de sua história. No dia seguinte, aproximadamente $182 \mathrm{hm}^{3}$ foram adicionados a estas reservas elevando-as para aproximadamente $26 \%$. Tal reserva deverá ser suficiente para garantir o abastecimento até o início da próxima estação chuvosa desde que as medidas de gestão de demanda tenham continuidade e, em caso de necessidade, sejam aprofundadas.

- O bombeamento do Volume Morto é medida de emergência, absolutamente necessária para enfrentar a atual crise, pois constitui a única alternativa viável, a curto prazo, de aumentar a oferta de água ao Sistema Cantareira. A situação, porém, está muito longe de ser confortável e exigirá o bombeamento de volumes adicionais mediante a construção de novas obras.

- A questão da qualidade das águas bombeadas que, em princípio, poderia inspirar cuidados, não representa impeditivo do aproveitamento destas águas, pelas razões apontadas acima.

Em que pese o aporte significativo de água, propiciada pela utilização de parte do volume morto, a economia de água pelos consumidores e as medidas de gestão da demanda por parte das instituições responsáveis deverão continuar e provavelmente precisarão ser mais rigorosas ao longo deste e do próximo ano.

Nos tempos de Quaresma precisamos refletir sobre nossas ações passadas e nossas atitudes com relação ao futuro. A ressurreição do Volume Morto foi necessária, mas não pode ser renovada a cada ano, a exemplo do que ocorre na fé cristã.

\section{Referências}

CETESB, Site da Internet, http://www.cetesb. sp.gov.br/agua/aguas-superficiais/35-publicacoes-/-relatorios

DAEE, 1968, Desenvolvimento Global dos Recursos Hidricos das Bacias do Alto Tiete e Cubatão- Plano Diretor de Obras- Secretaria dos Servicos e Obras Publicas. Departamento de Aguas e Energia Eletrica- DAEE 1968.

DAEE, 2004, Portaria DAEE 1213/2004,Renovação da Outorga do Sistema Cantareira

PORTO, M.F.A., Simulação da estratificação térmica do reservatório do Jacareî”, IX Simpósio Brasileiro de Recursos Hídricos, ABRH, Rio de Janeiro, novembro de 1991.

Sabesp, 1989 Data Oper-Sistema Cantareira. São Paulo. - Ed.Governo do Estado de São Paulo, 1989.--82p.

SOBRE OS AUTORES

Rubem L. Porto

Professor Senior da Escola Politécnica da USP

Monica F. A. Porto

Professora Titular da Escola Politécnica da USP

Marco Palermo

Doutor em Engenharia de Recursos Hídricos pela Escola Politécnica da USP

Endereço para Correspondência: Universidade de São Paulo, Escola Politécnica, Departamento de Engenharia Hidráulica e Sanitária. Av. Prof. Almeida Prado, 83, travessa 2 Cidade Universitária - Sao Paulo, SP - Brasil. CEP: 05508-900 Telefone: (11) 30915549 - Fax: (11) 30915423 email: rlporto@usp.br 